\title{
ARTICLE
}

\section{A biomimetic redox flow battery based on flavin mononucleotide}

Akihiro Orita ${ }^{1,2}$, Michael G. Verde ${ }^{1}$, Masanori Sakai ${ }^{2} \&$ Ying Shirley Meng ${ }^{1}$

The versatility in design of redox flow batteries makes them apt to efficiently store energy in large-scale applications at low cost. The discovery of inexpensive organic electroactive materials for use in aqueous flow battery electrolytes is highly attractive, but is thus far limited. Here we report on a flow battery using an aqueous electrolyte based on the sodium salt of flavin mononucleotide. Flavins are highly versatile electroactive molecules, which catalyse a multitude of redox reactions in biological systems. We use nicotinamide (vitamin B3) as a hydrotropic agent to enhance the water solubility of flavin mononucleotide. A redox flow battery using flavin mononucleotide negative and ferrocyanide positive electrolytes in strong base shows stable cycling performance, with over $99 \%$ capacity retention over the course of 100 cycles. We hypothesize that this is enabled due to the oxidized and reduced forms of FMN-Na being stabilized by resonance structures.

\footnotetext{
${ }^{1}$ Department of NanoEngineering, University of California, San Diego, 9500 Gilman Drive, La Jolla, California 92093, USA. ${ }^{2}$ Core Technology Research \& Innovation Center, Hitachi Chemical, 2200, Oka, Fukaya-shi, Saitama 369-0297, Japan. Correspondence and requests for materials should be addressed to Y.S.M. (email: shmeng@ucsd.edu).
} 
R enewable energy power generation, such as from solar and wind, is highly attractive, but their intermittent nature is problematic. To compensate for this drawback, the use and development of appropriate energy-storage systems have been heavily pursued. Redox flow batteries (RFBs) have been attracting much attention for use as grid-scale storage because of unique advantages they present, such as their flexible, modular design and fast response time ${ }^{1-4}$. An RFB stores its energy using redox active materials dissolved in electrolyte, referred to as positive and negative electrolytes, which are separated by a membrane and circulated by pumps. While a number of RFBs use safe or inexpensive or high-energy density materials, combining all three important criteria into one has not yet been achieved. For example, vanadium RFBs have been the most successfully commercialized thus far, but the use of rare-metal ions, in vanadium, leads to quite expensive systems ${ }^{5}$. While less energy dense, RFBs using organic active materials have received increasing interest because of their promise to satisfy other important requirements such as low cost and sustainability. A variety of unique organic active materials have been reported for use in $\mathrm{RFBs}^{3,6-13}$, a number of which have been inspired by research in Li-ion and Na-ion batteries ${ }^{14-16}$. The number of organic materials that can deliver stable cycling, however, has been very limited. The anthraquinone/bromide flow battery is one bright example, exhibiting stable performance over the course of 750 cycles $^{17,18}$. Understanding and translating the beneficial properties contributing to quinone systems' stabilities should be a major goal in the development of alternative organic RFB systems.

Flavins act as a cofactor in many enzymes that catalyse a wide variety of biological reactions, and contain one of the most versatile in vivo redox centres ${ }^{19,20}$. The planar isoalloxazine ring forms the basic structure for riboflavin, flavin mononucleotide $(\mathrm{FMN})$, and flavin adenine dinucleotide (FAD). The relationship of FMN-Na to the derivatives mentioned is illustrated in Supplementary Fig. 1a. The biosynthetic enzyme, flavokinase, catalyses the initial phosphorylation of riboflavin from adenosine triphosphate (ATP) to form FMN ${ }^{21}$. A fraction of FMN directly acts as a coenzyme. The large fraction of FMN combines with a second molecule of ATP to form FAD catalysed by FAD synthetase. Inspired by these biochemicals, flavins, such as riboflavin and lumichrome, have been demonstrated as solidstate electroactive materials for Li-metal batteries ${ }^{22,23}$. The concentration of flavins in those composite electrodes was no $>50 \mathrm{wt} \%$, however, due to the high content of conductive carbon necessary to compensate for their low electronic conductivity. In nature, flavins are often found dissolved in water, fat, or blood, such as in biological systems. As they are commonly more useful in this state, so may it also be in batteries. Interestingly, flavins have yet to be reported as an active material for any RFB, to the best of our knowledge.

In this study, we create a stable biomimetic RFB using a sodium salt of flavin mononucleotide (FMN-Na, Fig. 1a), known as riboflavin- $5^{\prime}$-phosphate sodium salt, which serves as negative electrolyte. Figure $1 \mathrm{~b}$ shows its schematic representation with potassium ferrocyanide, $\mathrm{K}_{4}\left[\mathrm{Fe}(\mathrm{CN})_{6}\right]$, as positive electrolyte, selected as one of many candidate redox couples (Fig. 1c), because of its stable reversibility under a strongly alkaline condition $^{13}$. We henceforth refer to this RFB chemistry as FMN/Fe. Here we explore the use of FMN-Na in aqueous RFBs due to its relatively high water solubility compared with other flavins, such as riboflavin (vitamin B2) and lumiflavin. To increase its water solubility further, nicotinamide (NA), known as vitamin B3 (Supplementary Fig. 1b), was used as a biomolecular a<smiles>Cc1cc2nc3c(=O)[nH]c(=O)nc-3n(CC(O)C(O)C(O)COP(=O)(O)O[Na])c2cc1C</smiles>

b
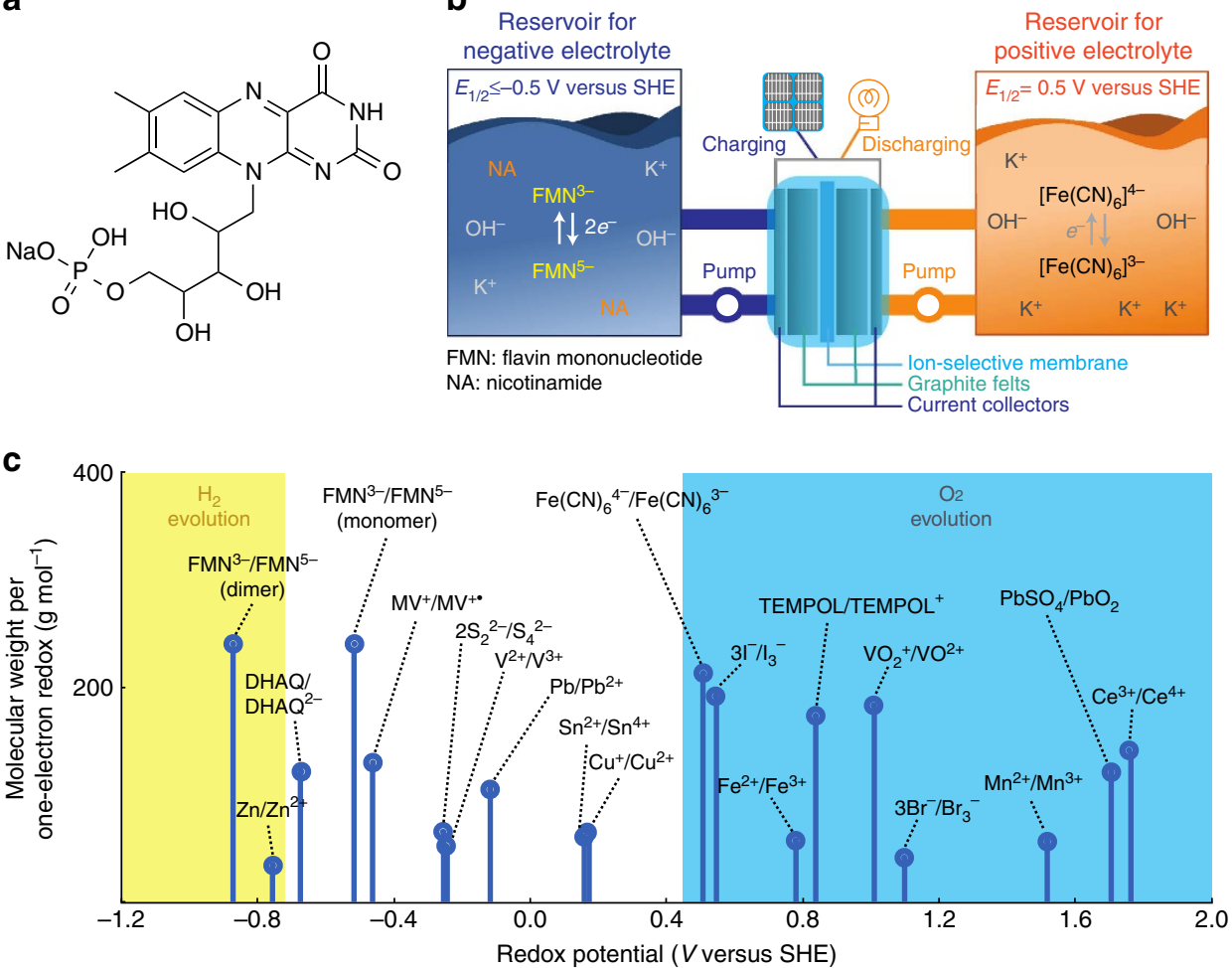

Figure 1 | Cell schematic of an FMN/Fe battery. (a) The molecular structure of riboflavin-5'-monophosphate sodium salt (FMN-Na, sodium salt of flavin mononucleotide). (b) Schematic representation of an RFB consisting of FMN-Na and ferrocyanide-based negative and positive electrolytes, respectively. (c) The redox potentials of various candidate redox couple highlighting regions of $\mathrm{H}_{2}$ evolution (yellow) and $\mathrm{O}_{2}$ evolution (blue) at pH 13. TEMPOL, 4-hydroxy-2,2,6,6-tetramethylpiperidin-1-oxyl; DHAQ, 2, 6-dihydroxyanthraquinone; MV, methyl-viologen. 
a<smiles></smiles>

b<smiles></smiles><smiles>Cc1cc2c(cc1C)N(CC(O)C(O)C(O)COP(=O)([O-])O)C1=NC(=O)[N-]C(O)C1=N2</smiles><smiles>Cc1cc2c(cc1C)N(CC(O)C(O)C(O)COP(=O)([O-])[O-])c1nc(=O)[n-]c([O-])c1[N-]2</smiles>

Figure 2 | Chemical structures of FMN-Na. (a) FMN-Na at various protonation states of the phosphate group and third position nitrogen. (b) Two-electron redox reaction mechanism of $\mathrm{FMN}-\mathrm{Na}$ in strongly alkaline conditions $(\mathrm{pH}>10.2)$.

additive in FMN-Na electrolyte. NA, urea, and caffeine are known as hydrotropic agents, and their addition has been reported to enhance the water solubility of poorly water-soluble drugs, including flavins ${ }^{24-28}$. FMN/Fe RFBs with this design are shown to achieve stable cycling performance with a capacity retention of $\sim 99 \%$ after 100 cycles. We propose that the superior performance of $\mathrm{FMN} / \mathrm{Fe} \mathrm{RFBs}$ is enabled by resonance structures, which can stabilize oxidized and reduced forms of FMN-Na. This study provides a promising strategy to design energy storage system using organic active materials.

\section{Results}

Effects of $\mathbf{p H}$ on FMN-Na redox. The electrochemistry of FMN-Na aqueous electrolyte was examined using cyclic voltammetry at various $\mathrm{pH}$ levels. The electronic structure of FMN has been previously studied in regard to biochemical applications, using ultraviolet-vis (ultraviolet-visible) spectroscopy and electron paramagnetic resonance ${ }^{29-32}$. Its electron-transfer mechanism in water has also been reported ${ }^{33}$. In an acidic aqueous solution $(0.7<\mathrm{pH}<6.2)$, the predominant species is $\mathrm{FMN}^{-}$, whereby a proton from the phosphate group of FMN has been lost (Fig. 2a). In near-neutral and weakly basic solutions $(6.2<\mathrm{pH}<10.2)$, the phosphate group loses a second proton, forming $\mathrm{FMN}^{2-}$. Furthermore, in a strong base $(\mathrm{pH}>10.2)$, FMN can lose an additional proton from the nitrogen $(\mathrm{N})$ located at the third position of the isoalloxazine ring to form $\mathrm{FMN}^{3-}$. For reasons described in the following sections, we mainly explore the use of FMN in flow batteries under these strongly basic conditions. Figure $2 \mathrm{~b}$ illustrates its redox reaction at $\mathrm{pH}>10.2$, whereby $\mathrm{FMN}^{3-}$ undergoes a two-electron reduction to form $\mathrm{FMN}^{5-}$. Due to the fact that FMN has been primarily studied in biological systems, and high $\mathrm{pH}$ conditions are uncommon in those environments, its electrochemistry in strongly basic conditions $(\mathrm{pH}>12)$ has not yet been thoroughly investigated.

Figure $3 \mathrm{a}$ shows the cyclic voltammograms (CVs) using $10 \mathrm{mM}$ FMN-Na at $\mathrm{pH} 5.5,8.6,10.0$, and 13.0. At low $\mathrm{pH}(\mathrm{pH}=5.5)$, two peaks for both oxidation and reduction can be observed. This is indicative of a two-step redox mechanism, proceeding through the stable intermediate shown in Supplementary Fig. 2a. At pH 8.6 and 10.0, only one redox peak is observed, centred at $\sim-0.5 \mathrm{~V}$ versus $\mathrm{Ag} / \mathrm{AgCl}$, which suggests that the two-electron reaction proceeds in a concerted manner ${ }^{30-32}$. Furthermore, this result shows that $\mathrm{FMN}^{2-}$ is stable in this $\mathrm{pH}$ range, as the $\mathrm{CVs}$ do not change from 8.6 to 10.0. In general, the redox potential of reactions involving proton exchange shifts as a function of $\mathrm{pH}$, based on the Nernst equation: $\Delta E=-m / n \quad 0.059 \times \mathrm{pH}$ at a temperature of $298 \mathrm{~K}$, where $\Delta E$ is the shift from the standard redox potential, and $\mathrm{m}\left(\mathrm{mH}^{+}\right)$and $\mathrm{n}\left(n e^{-}\right)$are the number of protons and electrons involved in the redox reaction, respectively. Since no voltage shift occurs in the $\mathrm{pH}$ range of $8.6-10.0$, this indicates that the redox reaction of $\mathrm{FMN}^{2}-$ does not directly involve proton exchange, as shown by the mechanism provided in Supplementary Fig. 2b.

At $\mathrm{pH}$ 13.0, a significant cathodic shift in the redox potential is observed, which can be explained by the fact that $\mathrm{FMN}^{3-}$ is less likely reduced, due to its large negative charge compared with $\mathrm{FMN}^{2-}$ or $\mathrm{FMN}^{-}$. The oxidation and reduction peak separation at $\mathrm{pH} 13.0$ is $48 \mathrm{mV}$, which is larger than the theoretical value expected for a reversible two-electron reaction $(28.5 \mathrm{mV})$. This suggests that the FMN-Na redox reaction can be described as a quasi-reversible reaction. Nevertheless, the peak separation and current density at $\mathrm{pH} 13.0$ were much improved compared with lower $\mathrm{pH}$. From these results, the strongly alkaline condition is shown to be preferable for FMN-Na used as negative electrolyte. This concept along with the detailed kinetics of $\mathrm{FMN}^{3-}$ is more thoroughly described in later sections of this paper.

Dimerization of FMN-Na. In alkaline conditions, FMN is known to exhibit photoinduced electron transfer $^{33}$ and undergo hydrolysis with $\mathrm{OH}^{-}$at high temperature $(353 \mathrm{~K})^{34,35}$. For this reason, we aimed to explore the temporal stability of the FMN-Na redox reaction. Figure $3 \mathrm{~b}$ shows the CVs of FMN-Na in $1 \mathrm{M} \mathrm{KOH}$ aqueous electrolyte ( $\mathrm{pH} 13.0$ ), up to $100 \mathrm{~h}$ after its preparation. The initial redox couple was centred at $-0.730 \mathrm{~V}$ versus $\mathrm{Ag} / \mathrm{AgCl}$. Over time, however, the peak intensity at this location decreased, while a redox couple at more negative potential developed. The developing reduction peak was located at $-1.15 \mathrm{~V}$, while its reversible oxidation peak was more broadly located between -0.85 and $-1.2 \mathrm{~V}$ versus $\mathrm{Ag} / \mathrm{AgCl}$. It should be noted that the temporal change in CVs could be observed regardless of the presence or absence of fluorescent light or oxygen gas in the electrolyte (controlled by $\mathrm{N}_{2}$ purging).

To first examine the possibility that hydrolysis of FMN-Na caused a change in the CVs over time, the CV of $10 \mathrm{mM}$ FMN-Na 

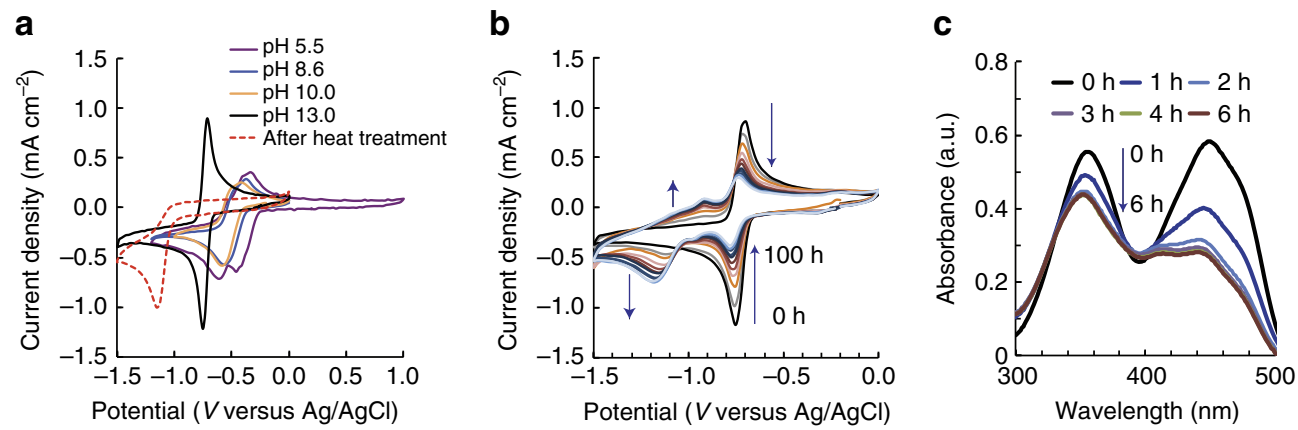

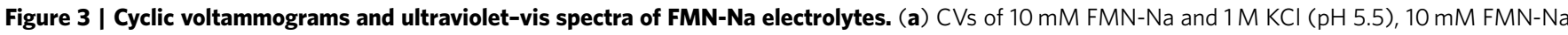

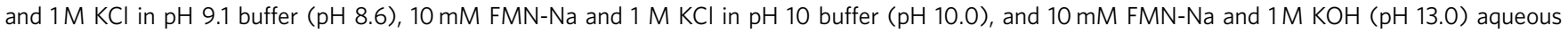
solutions; the dashed $\mathrm{CV}$ represents the latter electrolyte after treatment at $363 \mathrm{~K}$ for $2 \mathrm{~h}$. (b) $\mathrm{CVs}$ of $10 \mathrm{mM} \mathrm{FMN-Na} 1 \mathrm{M} \mathrm{KOH}$ aqueous electrolyte at $10 \mathrm{~h}$ intervals over the course of $100 \mathrm{~h}$ (sweep rate: $10 \mathrm{mVs}^{-1}$ ). (c) Ultraviolet-vis spectra of $50 \mu \mathrm{M}$ FMN-Na in $1 \mathrm{M} \mathrm{KOH}$ aqueous electrolyte $0-6 \mathrm{~h}$ after electrolyte preparation.

in $1 \mathrm{M} \mathrm{KOH}$ aqueous electrolyte was measured after heating to $363 \mathrm{~K}$. High temperatures are known to decompose FMN by the hydrolysis reaction shown in Supplementary Fig. 3 (ref. 35). As shown by the CV in Fig. 3a (dashed), the hydrolysed product exhibits only a negative current, indicating an irreversible redox reaction. The new peak formed over time at room temperature, however, is reversible (Fig. 3b). We conclude, therefore, that hydrolysis does not contribute to the formation of the second peak, and is likely negligible near room temperature. The reversibility of this second peak is further demonstrated in the full-cell testing section described later.

We also performed temporal ultraviolet-vis measurements using $50 \mu \mathrm{M}$ FMN-Na in $1 \mathrm{M} \mathrm{KOH}$ aqueous electrolyte up to $6 \mathrm{~h}$ after electrolyte preparation (Fig. 3c). The absorption peaks observed at 375 and $450 \mathrm{~nm}$, which can be assigned to $\pi \rightarrow \pi^{*}$ transitions ${ }^{36}$, decreased over time, up to $3 \mathrm{~h}$. A factor that may contribute to the evolving redox reaction and the decrease in absorption over time may be due to the dimerization of FMN-Na. The observed decrease in ultraviolet-vis absorption was not due to the alkaline hydrolysis of FMN-Na because the decrease could be observed even at pH 5.5 and 8.6 (Supplementary Fig. 4). On the basis of NMR analysis, FMN has been known to stack with itself in aqueous solution, to form dimers ${ }^{33,37,38}$. Furthermore, the extinct coefficient of its dimer is lower than that of its monomer at $\mathrm{pH} 7$ (ref. 39). Its formation could, therefore, result in the decreased absorbance measured. The dipole-dipole interaction of stacked monomers generally lowers its energy states $^{37}$, leading to higher reduction energies, which could also explain the cathodic potential shift observed. The fact that $\mathrm{CV}$ measurements were shown to continuously change up to $>100 \mathrm{~h}$, while the ultraviolet-vis spectra showed no change after $3 \mathrm{~h}$, may be due to the differences in concentration of those electrolytes (10 mM versus $50 \mu \mathrm{M}$ FMN-Na, respectively). The equilibrium constant of dimer formation has been reported to depend on the concentration of monomer at $\mathrm{pH} 7$ (ref. 39), and our future studies aim to examine this equilibrium in strong base.

Kinetics of FMN-Na. To expand upon the kinetics of FMN-Na, its diffusion coefficient and kinetic rate constant were investigated using rotating disk electrode (RDE) at a $\mathrm{pH}$ of 13.0. Figure $4 \mathrm{a}$ illustrates the limiting diffusion current at various rotating angular velocities of the electrode, ranging from 200 to 3,000 r.p.m., using electrolyte immediately following preparation. The half-wave potential $\left(E_{1 / 2}\right)$ of FMN-Na was $-0.726 \mathrm{~V}$ versus $\mathrm{Ag} / \mathrm{AgCl}(-0.517 \mathrm{~V}$ versus SHE) at a $\mathrm{pH}$ of 13 . Figure $4 \mathrm{~b}$ displays the dependence of the limiting current on rotating velocity. The fact that the linear trend line crosses the origin means that there was no observed chemical reaction that preceded or followed the redox reaction of FMN-Na electrolytes in the time frame used within the experiment. The diffusion coefficient of FMN-Na was determined to be $(1.3 \pm 0.1) \times 10^{-6} \mathrm{~cm}^{2} \mathrm{~s}^{-1}$ using the Levich equation ${ }^{40}$. Figure 4c shows Koutecký-Levich plots, which provide the heterogeneous rate constant $i_{\mathrm{k}}$ at each potential. $i_{\mathrm{k}}$ represents the current in the absence of any mass-transport effects, and can be observed for only quasi-reversible and irreversible reactions ${ }^{41}$. These values were used to form the Tafel plot shown in Fig. 4d, which exhibits good linearization. From this plot, the transfer coefficient for the reduction of FMN-Na was calculated to be $\alpha=0.50$. This value indicates that the energy barriers for oxidation and reduction of FMN-Na are symmetric ${ }^{42}$. The kinetic rate constant for the reduction of FMN-Na was determined to be $k_{0}=(5.3 \pm 0.5) \times 10^{-3} \mathrm{~cm}^{2} \mathrm{~s}^{-1}$, which is greater than those for inorganic redox couples, such as $V^{3+} / V^{2+}\left(5.3 \times 10^{-4} \mathrm{~cm} \mathrm{~s}^{-1}\right)$ (ref. 43) and $\mathrm{VO}^{2+} / \mathrm{VO}_{2}^{+}\left(2.8 \times 10^{-6} \mathrm{~cm} \mathrm{~s}^{-1}\right) \quad$ (ref. 43) (Supplementary Table 1). Future studies aim to explore the effect of dimerization on those kinetic parameters.

Electrochemistry of an FMN/Fe redox flow battery. Initial FMN/Fe RFBs were tested using $0.06 \mathrm{M}$ FMN-Na and $0.1 \mathrm{M}$ $\mathrm{K}_{4}\left[\mathrm{Fe}(\mathrm{CN})_{6}\right]$ in $1 \mathrm{M} \mathrm{KOH}$ at a current density of $5-20 \mathrm{~mA} \mathrm{~cm}^{-2}$. The CV and RDE measurements using $20 \mathrm{mM} \mathrm{K}_{4}\left[\mathrm{Fe}(\mathrm{CN})_{6}\right]$ and $1 \mathrm{M} \mathrm{KOH}$ aqueous positive electrolyte are shown in Supplementary Fig. 5. The excess amount of FMN-Na was used because the purity of FMN-Na was $>93 \%$ based on anhydrate and easily hydrated. Figure $5 \mathrm{a}$ illustrates the charge-discharge curves at a current density of 5,10 , and $20 \mathrm{~mA} \mathrm{~cm}^{-2}$. The initial discharge capacity at $10 \mathrm{~mA} \mathrm{~cm}^{-2}$ was $1.31 \mathrm{Ahl}^{-1}$, which is close to the theoretical capacity of $1.34 \mathrm{Ahl}^{-1}$. The opencircuit voltage (OCV) at $100 \%$ SOC and the average discharge voltage at a current density of $10 \mathrm{~mA} \mathrm{~cm}^{-2}$ were $1.40 \mathrm{~V}$ and $1.03 \mathrm{~V}$, respectively. The charging curve shows two plateaus around $1.15 \mathrm{~V}$ and $1.50 \mathrm{~V}$, which we hypothesize results from reduction of the monomer and dimer of FMN-Na, respectively. Interestingly, the discharge curve does not mirror the two discrete plateaus observed on charge curve. The oxidation peak of the dimer measured using CV (Fig. 3a) was also quite broad. In addition, the high-voltage plateau became less distinct with higher current densities, which resulted in lower charge capacities overall. This phenomenon may be explained by the lower kinetic rate of dimer $\mathrm{FMN}-\mathrm{Na}$ than that of monomer FMN-Na. Figure 5b,c show the charge-discharge profiles, 
a

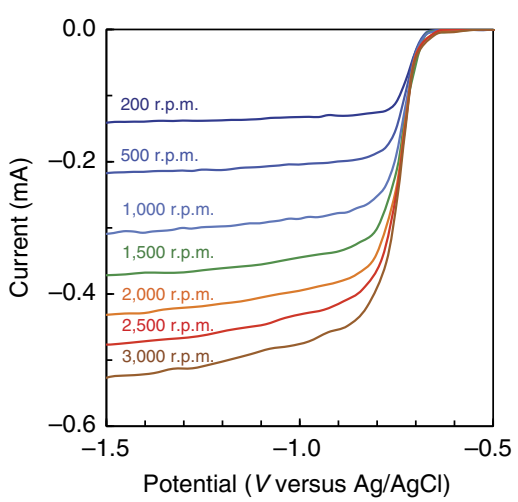

C

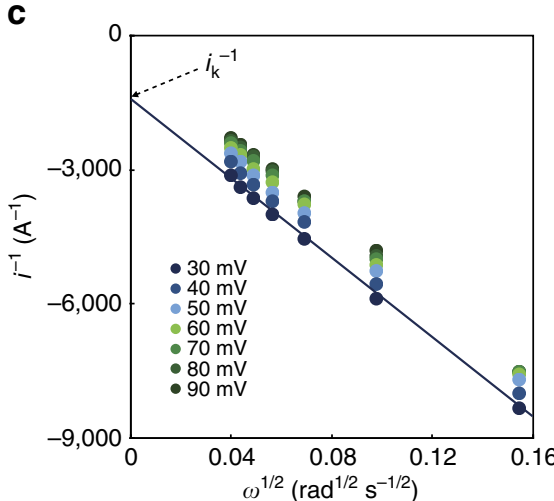

b

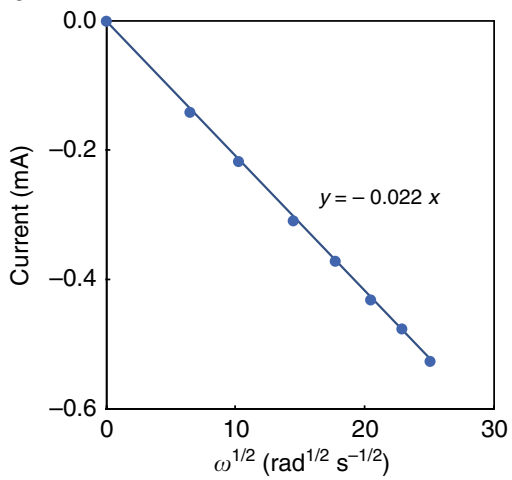

d

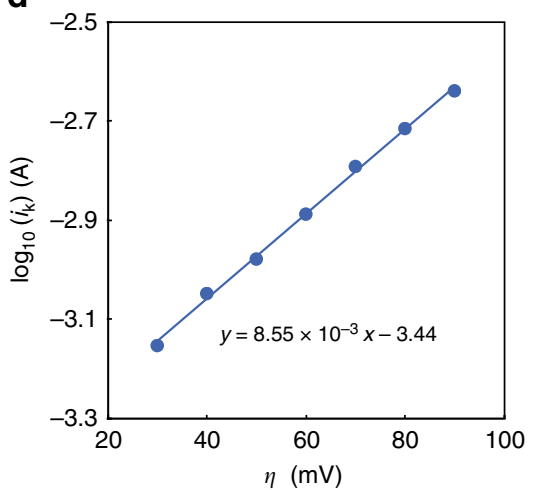

Figure 4 | Electrochemistry of an FMN-Na electrolyte. (a) RDE measurements at rotating electrode speeds from 200 to 3,000 r.p.m. using 10 mM FMN$\mathrm{Na}$ in $1 \mathrm{M} \mathrm{KOH}$ aqueous solution $(\mathrm{pH}=13.0)$. (b) The limiting current (i) versus the square root of the rotation velocity (Levich-plot). (c) Koutecký-Levich plot. (d) Tafel plot. $\eta$ is the difference between the measured potential and the formal redox potential.
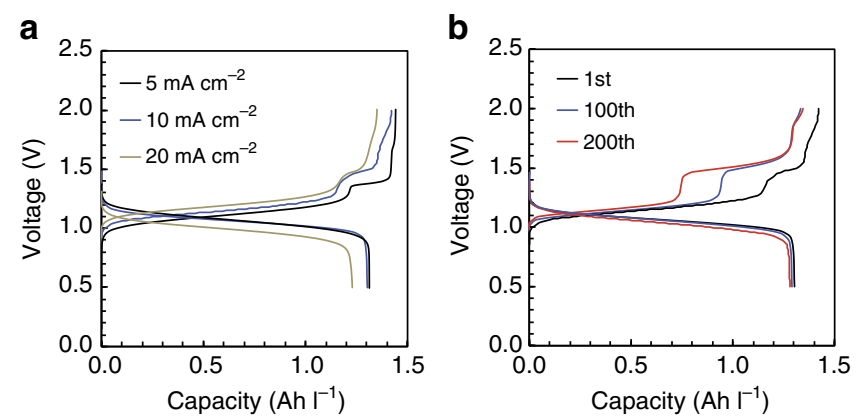

c

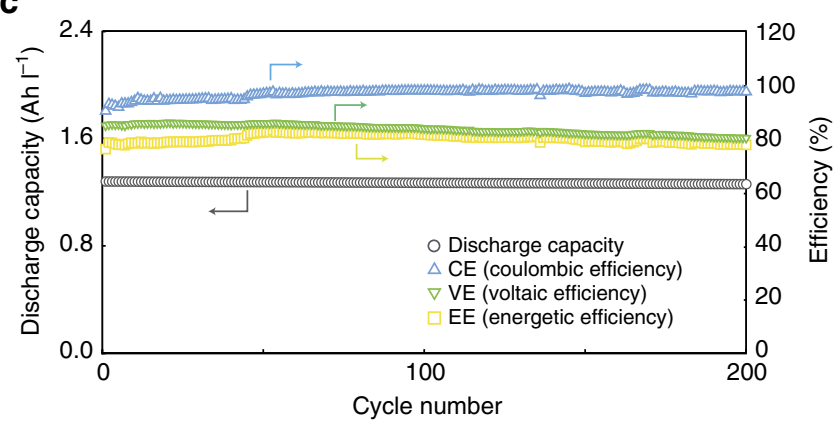

Figure 5 | Electrochemistry of an FMN/Fe RFB at a low concentration.

$0.1 \mathrm{M} \mathrm{K}_{4}\left[\mathrm{Fe}(\mathrm{CN})_{6}\right]$ in $1 \mathrm{M} \mathrm{KOH}$ aqueous positive electrolyte and $0.06 \mathrm{M}$ FMN-Na in $1 \mathrm{M} \mathrm{KOH}$ aqueous negative electrolyte were used. (a) Chargedischarge profiles at a current density of 5,10 and $20 \mathrm{~mA} \mathrm{~cm}^{-2}$. (b) Charge-discharge profiles at 1st, 100 th, and 200 th cycles at $10 \mathrm{~mA} \mathrm{~cm}^{-2}$. (c) Cycling discharge capacity and efficiencies of an RFB at a current density of $10 \mathrm{mAcm}^{-2}$. discharge capacities and efficiencies over a number of cycles. Highly stable discharge capacities are observed over the course of 200 cycles, which took $124 \mathrm{~h}$. The Coulombic efficiency improves slightly over time, which is associated with the significant extension of the high voltage plateau due to dimer reduction. Voltage efficiency slightly decreased on cycling due to the increasing proportion of dimer reduction, which takes place at slightly higher voltages.

We hypothesize that the stable cyclability is in part enabled by the resonance structures of oxidized and reduced forms of FMN-Na, as shown in Supplementary Fig. 6 (refs 44,45). A variety of resonance structures lead to electron delocalization, which lowers the overall potential energy of FMN-Na, thereby making it less prone to decomposition. The general ability of resonance states to stabilize organic redox species can be adapted to explain the durability of other compounds, such as those that are quinonebased, as well. The resonance structures of anthraquinone, which was stably cycled in the quinone/Br system for 750 cycles $^{18}$, are shown in Supplementary Fig. 7a. On the contrary, the worse cycling ability of benzoquinone $e^{9}$ compared with anthraquinone may be explained by its relatively poor diversity of resonance structures at the reduced state (Supplementary Fig. 7b). From these trends, we propose that the stabilization of redox pairs by resonance structures can be a promising strategy to design energy storage systems based on organic active materials.

Energy-density enhancement. The full-cell performance of FMN/Fe RFB was investigated at a higher concentration to assess the limits of its energy density and cycling performance under ideal working conditions. The maximum water solubility of $\mathrm{K}_{4}\left[\mathrm{Fe}(\mathrm{CN})_{6}\right]$ in $1 \mathrm{M} \mathrm{KOH}$ aqueous solutions at $298 \mathrm{~K}$ was 
a

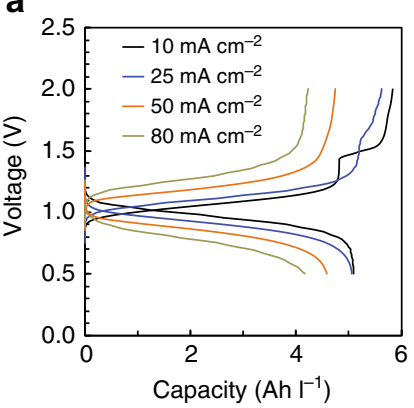

b

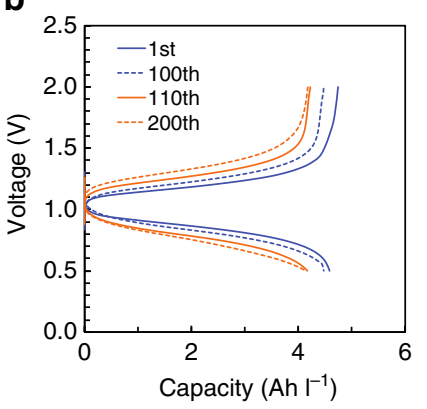

C

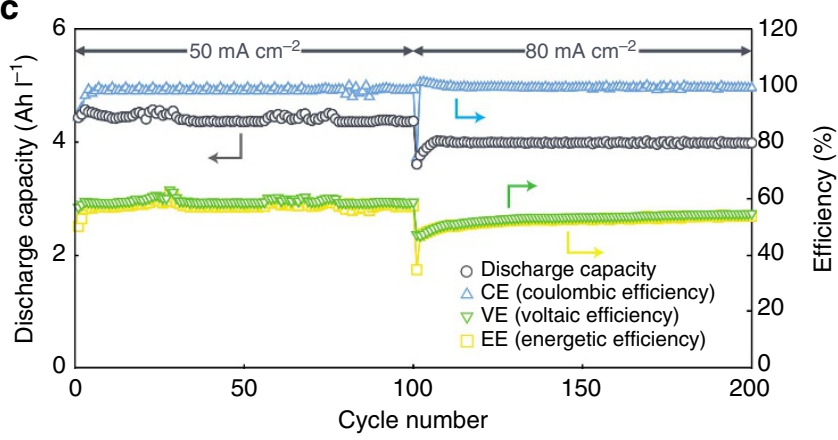

d

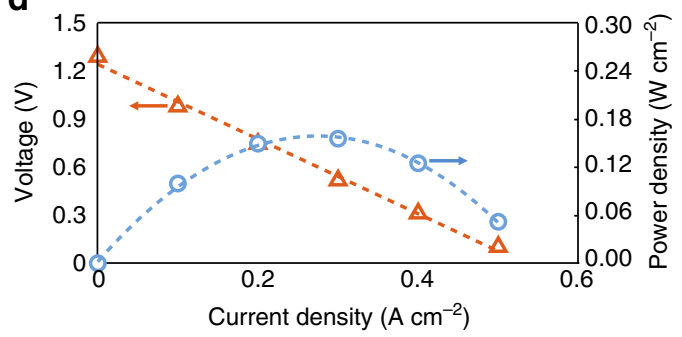

Figure 6 | Electrochemical performance of an FMN/Fe RFB at a high

concentration. $0.4 \mathrm{M} \mathrm{K}_{4}\left[\mathrm{Fe}(\mathrm{CN})_{6}\right]$ in $1 \mathrm{M} \mathrm{KOH}$ aqueous positive electrolyte and $0.24 \mathrm{M} \mathrm{FMN-Na}$ and $1 \mathrm{M} \mathrm{NA}$ in $1 \mathrm{M} \mathrm{KOH}$ aqueous negative electrolyte were used. (a) Charge-discharge profiles at 10, 25, 50 and $80 \mathrm{~mA} \mathrm{~cm}^{-2}$. (b) Charge-discharge curves at $1^{\text {st }}$ and 100th cycles at $50 \mathrm{~mA} \mathrm{~cm}^{-2}$, and 110th and 200th cycles at $80 \mathrm{mAcm}^{-2}$. (c) Cycling discharge capacities and efficiencies. (d) Voltage- and power-density dependencies on discharge current density.

$\sim 0.5 \mathrm{M}$. As highlighted in Supplementary Fig. 8a, the water solubilities of FMN-Na in $1 \mathrm{M} \mathrm{H}_{2} \mathrm{SO}_{4}(\mathrm{pH} 0.8), 1 \mathrm{M} \mathrm{KCl}(\mathrm{pH} 5.5)$ and $1 \mathrm{M} \mathrm{KOH}$ aqueous solutions ( $\mathrm{pH} 13.0$ ) were determined to be $\sim 10,50$ and $100 \mathrm{mM}$, respectively. The highest water solubility in strongly alkaline conditions may be explained by the fact that FMN-Na has higher polarity than in acidic or neutral solution due to the large negative charge $\left(\mathrm{FMN}^{3-}\right)$, which results in the most stable solvated state by water. To further enhance the water solubility of FMN-Na, NA (nicotinamide) was added as a hydrotropic agent ${ }^{24}$. FMN-Na showed a maximum solubility of $\sim 1.5 \mathrm{M}$ in an aqueous solution of $1.0 \mathrm{M} \mathrm{KOH}$ by adding $3 \mathrm{M} \mathrm{NA}$ (Supplementary Fig. 8b). The viscosity of this electrolyte increased to $3.2 \mathrm{mPa}$, compared with the $0.06 \mathrm{M}$ FMN-Na $1 \mathrm{M}$ $\mathrm{KOH}$ solution of $1.2 \mathrm{mPas}$. Determining the optimum concentrations of FMN-Na will be explored in the future studies. Supplementary Fig. 9a shows the CV of $10 \mathrm{mM}$ FMN$\mathrm{Na}$ with $10 \mathrm{mM}$ NA in $1 \mathrm{M} \mathrm{KOH}$. Compared with the $\mathrm{CV}$ in Fig. 3a, the peak potentials and shape do not change, indicating that the addition of NA has no effect on the redox reaction.

Figure 6a illustrates charge-discharge profiles of an RFB with $0.4 \mathrm{M} \mathrm{K}_{4}\left[\mathrm{Fe}(\mathrm{CN})_{6}\right]$ in $1 \mathrm{M} \mathrm{KOH}$ positive electrolyte and $0.24 \mathrm{M}$
FMN-Na and $1 \mathrm{M} \mathrm{NA}$ in $1 \mathrm{M} \mathrm{KOH}$ negative electrolyte at a current density of $10-80 \mathrm{~mA} \mathrm{~cm}^{-2}$. The two charge plateaus assigned to reductions of monomer and dimer FMN-Na can be observed only at a low current density $\left(10-25 \mathrm{~mA} \mathrm{~cm}^{-2}\right)$. The $\mathrm{CV}$ of $0.24 \mathrm{M}$ FMN-Na electrolyte also shows no distinct peak for the redox reaction of dimer at high sweep rates (Supplementary Fig. 9b,c). The initial capacity measured at a current density of $25 \mathrm{~mA} \mathrm{~cm}^{-2}$ was $5.03 \mathrm{Ah} \mathrm{l}^{-1}$, which was close to the theoretical capacity of $5.36 \mathrm{Ahl}^{-1}$. The OCV at $100 \%$ SOC and the average discharge voltage of the initial cycle at $25 \mathrm{~mA} \mathrm{~cm}^{-2}$ were $1.30 \mathrm{~V}$ and $0.96 \mathrm{~V}$, respectively, which delivered an energy density of $4.83 \mathrm{Whl}^{-1}$.

Figure $6 \mathrm{~b}, \mathrm{c}$ shows the cycling discharge capacities, efficiencies, and charge-discharge curves over 200 cycles, which took $76 \mathrm{~h}$, at a current density of 50 and $80 \mathrm{~mA} \mathrm{~cm}^{-2}$. The discharge capacity retention after 100 cycles was $99 \%$, and the Coulombic efficiency was $>99 \%$ at a current density of $80 \mathrm{~mA} \mathrm{~cm}^{-2}$. Their stabilities are comparable to the quinone system, and greater than other systems using organic active materials (Supplementary Table 2). In addition, no FMN-Na was detected in the positive electrolyte after 200 cycles (Supplementary Fig. 10), which suggests that crossover is not an issue, likely due to the negatively charged $\mathrm{FMN}^{3-}$ and $\mathrm{FMN}^{5-}$. The observed low capacity (1\% during 100 cycles) may be due to the alkaline hydrolysis even at room temperature or poor reversibility of dimer FMN-N. A hydrotropic agent has been reported to the ability to suppress the basecatalysed hydrolysis of riboflavin ${ }^{46}$, and our future studies aim for further improvement. To evaluate the power density of the RFB, a polarization curve was plotted, which is shown in Fig. 6d. The peak power density was determined to be $0.16 \mathrm{~W} \mathrm{~cm}^{-2}$ at a current density of $0.3 \mathrm{~A} \mathrm{~cm}^{-2}$, which is greater than the all-vanadium RFB $\left(0.12 \mathrm{~W} \mathrm{~cm}^{-2}\right.$ at $\left.0.15 \mathrm{~A} \mathrm{~cm}^{-2}\right)$. Currently, the full-cell energy density is limited by the solubility of the positive electrolyte. For one-electron process, the concentration of positive electrolyte should be $3 \mathrm{M}$ to make use of FMN's maximum solubility of $1.5 \mathrm{M}$ FMN-Na (with $3 \mathrm{M} \mathrm{NA}$ ). This negative electrolyte concentration will enable a full cell with high energy and power densities. We are currently exploring new active materials as high water solubility alternatives to $\mathrm{K}_{4}\left[\mathrm{Fe}(\mathrm{CN})_{6}\right]$.

\section{Discussion}

FMN-Na is composed of earth-abundant elements and is environmentally friendly. This work demonstrates that FMN-Na is a promising active material for sustainable RFBs. We propose that a variety of resonance structures of its reduced state enable stable redox cyclability. The future design and incorporation of resonance-stabilized active materials may be beneficial to the development of long-life energy storage systems. We have also shown that the hydrotropic agent nicotinamide, known as vitamin $\mathrm{B} 3$, demonstrates the ability to increase the solubility of FMN-Na. FMN-Na has a solubility $>1.5 \mathrm{M}$ with $3 \mathrm{M}$ NA (0.1 M without), and the FMN-Na solution can achieve the high capacity density of $81 \mathrm{Ahl}^{-1}$. Although materials with higher water solubility than $\mathrm{K}_{4}\left[\mathrm{Fe}(\mathrm{CN})_{6}\right]$ as positive electrolyte must be further explored to test the limits of FMN as a negative electrolyte, this study reveals its promise for use in RFBs.

Quinonic and flavin compounds, such as vitamins, FMN and nicotinamide adenine nucleotide (NAD), have been naturally selected for use in biochemical systems through the long evolutionary process. Thus, the biomimetic energy storage system described in this work is derived from nature's wisdom. Not only FMN-Na, but also other biochemicals found in cells, the citric acid cycle, enzymes and coenzymes, may inspire the design of sustainable energy storage systems. Recently, metal complexes based on biochemicals have been also proposed for $\mathrm{RFBs}^{3}$. 
Titanium complexes using catechol, pyrogallate, lactate and citrate, which can be found in plants and animals, have shown a reversible redox reaction ${ }^{47,48}$. Strategies inspired by biological systems, such as the utilization of hydrotropic agents and biochemicals, may expedite the successful exploration of sustainable ecofriendly batteries.

\section{Methods}

Materials. All chemicals were used as received without further purification. Riboflavin- $5^{\prime}$-phosphate sodium salt (FMN-Na, purity $\geq 93 \%$ based on the anhydrate substance) was purchased from TCI America. $96 \% \mathrm{H}_{2} \mathrm{SO}_{4}, \mathrm{Nafion} 212$, potassium ferrocyanide, potassium hydroxide, potassium chloride, nicotinamide and boric acid were obtained from Sigma-Aldrich. The $\mathrm{pH} 9.1$ buffer solution was prepared by adding $100 \mathrm{mM}$ boric acid and $50 \mathrm{mM} \mathrm{KOH}$ into deionized water. The $\mathrm{pH} 10$ buffer solution was purchased from Fisher Chemical. The $\mathrm{pH}$ levels of some solutions were adjusted using potassium hydroxide, $\mathrm{pH} 9.1$ buffer, and $\mathrm{pH} 10$ buffer solutions. The $\mathrm{pH}$ value of each electrolyte was measured with an Oakton $\mathrm{pH}$ meter ( $\mathrm{pH}-2700)$. The water solubility was examined at $288 \mathrm{~K}$.

Full-cell performance. Full-cell tests were carried out using an Arbin BT-2000 battery tester (Arbin Instrument) and RFB cell (Scribner Associates) comprised of poly(tetrafluoroethylene) (PTFE) frame, graphite plates with flow fields, anodized aluminum current collector, and graphite felt electrodes (GFA6, SGL) with an active area of $25 \mathrm{~cm}^{2}$. Galvanostatic evaluations were conducted at currents from 10 to $0.5 \mathrm{~A} \mathrm{~cm}^{-2}$ between 0 and $2.0 \mathrm{~V}$. Nafion 212 was used as an ion-exchange membrane after a treatment for exchanging $\mathrm{H}^{+}$with $\mathrm{K}^{+}$. This exchange procedure was carried out in $1 \mathrm{M} \mathrm{KOH}$ at $80^{\circ} \mathrm{C}$ for $6 \mathrm{~h}$, followed by being washed with deionized water, according to previous literature ${ }^{49}$. Forty millilitre of positive and negative electrolyte was pumped at a flow rate of $40 \mathrm{ml} \mathrm{min}^{-1}$ through a peristaltic pump. Coulombic efficiency, voltaic efficiency and energetic efficiency were calculated by the ratios of the average discharge capacity to the average charge capacity, the average discharge voltage to the average charge voltage and the average discharge energy to the average charge energy, respectively. Two FMN/Fe RFB compositions were primarily explored: the first was $0.1 \mathrm{M} \mathrm{K}_{4}\left[\mathrm{Fe}(\mathrm{CN})_{6}\right]$ and 1.0 M KOH aqueous positive electrolyte and $0.06 \mathrm{M} F M N-\mathrm{Na}$ in $1.0 \mathrm{M} \mathrm{KOH}$ aqueous negative electrolyte; the second was $0.4 \mathrm{M} \mathrm{K}_{4}\left[\mathrm{Fe}(\mathrm{CN})_{6}\right]$ and $1.0 \mathrm{M} \mathrm{KOH}$ aqueous positive electrolyte and $0.24 \mathrm{M}$ FMN-Na and $1 \mathrm{M}$ nicotinamide in $1.0 \mathrm{M}$ $\mathrm{KOH}$ aqueous negative electrolyte. An OCV was measured after the initial charge process at 10 or $20 \mathrm{~mA} \mathrm{~cm}^{-2}$. The capacity density was calculated based on the total volume of positive electrolyte $(40 \mathrm{ml})$ and negative electrolyte $(40 \mathrm{ml})$. Energy density was calculated by multiplying the discharge capacity and the average discharge voltage of the initial cycle.

Voltammetry. CV and RDE voltammetry were conducted using an Arbin BT-2000 battery tester (Arbin Instrument) and a BASi RDE-2. A BASi Ag/AgCl aqueous reference electrode (RE-5B, MF-2079, $3 \mathrm{M} \mathrm{NaCl}$ filling solution), platinum wire auxiliary counter electrode (MW-1033, $0.5 \mathrm{~mm}$ diameter) and glassy carbon working electrode (MF-2066, $3 \mathrm{~mm}$ diameter) was used. CV curves were measured at a sweep rate of $10 \mathrm{mV} \mathrm{s}^{-1}$.

For RDE experiments, current was measured from -0.2 to $-1.5 \mathrm{~V}$ versus $\mathrm{Ag} / \mathrm{AgCl}$ at a $5 \mathrm{mV} \mathrm{s}^{-1}$ sweep rate, during which time the electrode was rotated at 200-3,000 r.p.m. The half-wave potential $E_{1 / 2}$ was calculated as the voltage, which showed the half of the limiting current, at 200 r.p.m. The limiting currents measured at $-1.5 \mathrm{~V}$ were plotted versus the rotation rate $(\omega)$. The slope was fit using the Levich equation ${ }^{40}: i=0.620 n F A c D^{2 / 3} v^{-1 / 6} \omega^{1 / 2}$, where $i$ is the limiting current, $n$ is the number of electrons in the reaction ( $n=2$ for FMN-Na), $F$ is the Faraday constant $\left(96485 \mathrm{C} \mathrm{mol}^{-1}\right), A$ is the surface area of the working electrode $\left(0.0707 \mathrm{~cm}^{2}\right), c$ is molar concentration in mol cm ${ }^{-3}, v$ is the kinetic viscosity in $\mathrm{cm}^{2} \mathrm{~s}^{-1}\left(9.0 \times 10^{-3} \mathrm{~cm}^{2} \mathrm{~s}^{-1}\right.$ for $10 \mathrm{mM}$ FMN-Na and $1 \mathrm{M} \mathrm{KOH}$ aqueous solution) and $\omega$ is the routing angular velocity in $\operatorname{rads}^{-1}$. The heterogeneous rate constant was calculated from the vertical-axis intercepts at each potential using the Koutecký-Levich equation $^{40}: 1 / i=1 / i_{\mathrm{k}}+1 / 0.620 n F A c D^{2 / 3} v^{-1 / 6} \omega^{1 / 2}$. It should be noted that the Koutecký-Levich equation can only be used for quasi-reversible and irreversible reactions ${ }^{41} \cdot \log _{10}\left(i_{\mathrm{k}}\right)$ was plotted versus $\eta$, which was defined by the difference between the measured potential and the formal redox potential $E^{0^{\prime}}$. Here the half-wave potential at 200 r.p.m. was used as the formal redox potential $E^{0^{\prime}}$. The fitted line was expressed by the Tafel equation: $\log _{10}(i)=\log _{10}\left(n F c A k_{0}\right)+$ $\alpha n F \eta / 2.303 R T$, where $n$ is the number of electrons in the rate limiting step $(n=1 \text { for FMN-Na })^{50}, \alpha$ is the transfer coefficient, $R$ is the universal gas constant $\left(8.314 \mathrm{~J} \mathrm{~K}^{-1} \mathrm{~mol}^{-1}\right), T$ is temperature, $k_{0}\left(\mathrm{~cm} \mathrm{~s}^{-1}\right)$ is the standard kinetic rate constant, and the concentrations of redox couples were assumed to be the same.

Ultraviolet-vis spectroscopy. Ultraviolet-vis spectra were measured using a UV-VIS spectrometer UV-1800 (Shimadzu Scientific Instrument) and quartz spectrophotometer cells (Aldrich, $10 \mathrm{~mm}$ optical path length). The spectrum was measured at a wavelength range of $300-800 \mathrm{~nm}$ at a sampling interval of $0.5 \mathrm{~nm}$.
Data availability. The data that supports the findings of this study are available from the corresponding author on request.

\section{References}

1. Weber, A. Z. et al. Redox flow batteries: a review. J. Appl. Electrochem. 41, 1137-1164 (2011).

2. Wang, W. et al. Recent progress in redox flow battery research and development. Adv. Funct. Mater. 23, 970-986 (2013).

3. Soloveichik, G. L. Flow batteries: current status and trends. Chem. Rev. 115, 11533-11558 (2015).

4. Noack, J., Roznyatovskaya, N., Herr, T. \& Fischer, P. The chemistry of redoxflow batteries. Angew. Chem. Int. Ed. 54, 9775-9808 (2015).

5. Viswanathan, V. et al. Cost and performance model for redox flow batteries. J. Power Sources 247, 1040-1051 (2014).

6. Sevov, C. S. et al. Evolutionary design of low molecular weight organic anolyte materials for applications in nonaqueous redox flow batteries. J. Am. Chem. Soc. 137, 14465-14472 (2015).

7. Janoschka, T. et al. An aqueous, polymer-based redox-flow battery using non-corrosive, safe, and low-cost materials. Nature 527, 78-81 (2015).

8. Gong, K., Fang, Q. R., Gu, S., Li, S. F. Y. \& Yan, Y. S. Nonaqueous redox-flow batteries: organic solvents, supporting electrolytes, and redox pairs. Energy Environ. Sci. 8, 3515-3530 (2015).

9. Ding, Y. \& Yu, G. H. A bio-inspired, heavy-metal-free, dual-electrolyte liquid battery towards sustainable energy storage. Angew. Chem. Int. Ed. 55, 4772-4776 (2016).

10. Wei, X. L. et al. Radical compatibility with nonaqueous electrolytes and its impact on an all-organic redox flow battery. Angew. Chem. Int. Ed. 54, 8684-8687 (2015).

11. Yang, B., Hoober-Burkhardt, L., Wang, F., Prakash, G. K. S. \& Narayanan, S. R An inexpensive aqueous flow battery for large-scale electrical energy storage based on water-soluble organic redox couples. J. Electrochem. Soc. 161, A1371-A1380 (2014)

12. Brushett, F. R., Vaughey, J. T. \& Jansen, A. N. An all-organic non-aqueous lithium-ion redox flow battery. Adv. Energy Mater. 2, 1390-1396 (2012).

13. Lin, K. X. et al. Alkaline quinone flow battery. Science 349, 1529-1532 (2015).

14. Armand, M. et al. Conjugated dicarboxylate anodes for Li-ion batteries. Nat. Mater. 8, 120-125 (2009).

15. Haupler, B., Wild, A. \& Schubert, U. S. Carbonyls: powerful organic materials for secondary batteries. Adv. Energy Mater 5, 1402034 (2015).

16. Liang, Y. L., Tao, Z. L. \& Chen, J. Organic electrode materials for rechargeable lithium batteries. Adv. Energy Mater. 2, 742-769 (2012).

17. Huskinson, B. et al. A metal-free organic-inorganic aqueous flow battery. Nature 505, 195-198 (2014).

18. Huskinson, B., Marshak, M. P., Gerhardt, M. R. \& Aziz, M. J. Cycling of a quinone-bromide flow battery for large-scale electrochemical energy storage. ECS Trans. 61, 27-30 (2014).

19. Miura, R. Versatility and specificity in flavoenzymes: control mechanisms of flavin reactivity. Chem. Rec. 1, 183-194 (2001).

20. Massey, V. The chemical and biological versatility of riboflavin. Biochem. Soc Trans. 28, 283-296 (2000)

21. Zempleni, J. Handbook of Vitamins 4th edn (Taylor \& Francis, 2007).

22. Lee, M. et al. Redox cofactor from biological energy transduction as molecularly tunable energy-storage compound. Angew. Chem. Int. Ed. 52, 8322-8328 (2013)

23. Hong, J. et al. Biologically inspired pteridine redox centres for rechargeable batteries. Nat. Commun. 5, 9 (2014).

24. Coffman, R. E. \& Kildsig, D. O. Effect of nicotinamide and urea on the solubility of riboflavin in various solvents. J. Pharm. Sci. 85, 951-954 (1996).

25. Rasool, A. A., Hussain, A. A. \& Ditter, L. W. Solubility enhancement of some water-insoluble drugs in the presence of nicotinamide and related-compounds. J. Pharm. Sci. 80, 387-393 (1991).

26. Evstigneev, M. P., Eustigneev, V. P., Santiago, A. A. H. \& Davies, D. B. Effect of a mixture of caffeine and nicotinamide on the solubility of vitamin (B-2) in aqueous solution. Eur. J. Pharm. Sci. 28, 59-66 (2006).

27. Veselkov, A. N., Lantushenko, A. O., Chubarov, A. S., Veselkov, D. A. \& Davies, D. B. H-1 NMR analysis of the self-association of riboflavinmononucleotide and its complexation with nicotinamide in an aqueous solution. Russ. J. Phys. Chem. 76, 1350-1356 (2002).

28. Frost, D. V. The effect of nicotinamide of the solubility of riboflavin in water. J. Am. Chem. Soc. 69, 1064-1065 (1947).

29. Kammler, L. \& van Gastel, M. Electronic structure of the lowest triplet state of flavin mononucleotide. J. Phys. Chem. A 116, 10090-10098 (2012).

30. Astuti, Y. et al. Proton-coupled electron transfer of flavodoxin immobilized on nanostructured tin dioxide electrodes: Thermodynamics versus kinetics control of protein redox function. J. Am. Chem. Soc. 126, 8001-8009 (2004).

31. Tan, S. L., Kan, J. M. \& Webster, R. D. Differences in proton-coupled electrontransfer reactions of flavin mononucleotide (FMN) and flavin adenine dinucleotide (FAD) between buffered and unbuffered aqueous solutions. J. Phys. Chem. B 117, 13755-13766 (2013). 
32. Tan, S. L. J., Novianti, M. L. \& Webster, R. D. Effects of low to intermediate water concentrations on proton-coupled electron transfer (PCET) reactions of flavins in aprotic solvents and a comparison with the PCET reactions of quinones. J. Phys. Chem. B 119, 14053-14064 (2015).

33. Grajek, H. Resonance energy transfer between FMN molecules in the presence of dimers: a review. J. Mol. Liq. 209, 169-186 (2015).

34. Surrey, A. R. \& Nachod, F. C. Alkaline hydrolysis of riboflavin. J. Am. Chem. Soc. 73, 2336-2338 (1951)

35. Smith, S. B. \& Bruice, T. C. Mechanisms of Isoalloxazine (Flavine) hydrolysis. J. Am. Chem. Soc. 97, 2875-2881 (1975).

36. Heelis, P. F. The photophysical and photochemical properties of flavins (Iisoalloxazines). Chem. Soc. Rev. 11, 15-39 (1982).

37. Grajek, H., Zurkowska, G., Drabent, R. \& Bojarski, C. The structure of the flavomononucleotide dimer. Biochim. Biophys. Acta 881, 241-247 (1986).

38. Kainosho, M. \& Kyogoku, Y. High-resolution proton and phosphorus nuclear magnetic-resonance spectra of flavin-adenine dinucleotide and its conformation in aqueous-solution. Biochemistry 11, 741-752 (1972).

39. Grajek, H., Drabent, R., Zurkowska, G. \& Bojarski, C. Absorption of the flavin dimers. Biochim. Biophys. Acta 801, 456-460 (1984).

40. Treimer, S., Tang, A. \& Johnson, D. C. A consideration of the application of Koutecky-Levich plots in the diagnoses of charge-transfer mechanisms at rotated disk electrodes. Electroanalysis 14, 165-171 (2002).

41. Kim, J. \& Bard, A. J. Application of the koutecky-levich method to the analysis of steady state voltammograms with ultramicroelectrodes. Anal. Chem. 88, 1742-1747 (2016).

42. Allen, J. B. \& Larry, R. F. Electrochemical Methods: Fundamentals and Applications (John Wiley \& Sons, Inc, 2001).

43. Yamamura, T., Watanabe, N., Yano, T. \& Shiokawa, Y. Electron-transfer kinetics of $\mathrm{Np}^{3+} / \mathrm{Np}^{4+}, \mathrm{NpO}^{2+} / \mathrm{NpO}_{2}^{2+}, \mathrm{V}^{2+} / \mathrm{V}^{3+}$, and $\mathrm{VO}^{2+} / \mathrm{VO}_{2}^{+}$at carbon electrodes. J. Electrochem. Soc. 152, A830-A836 (2005).

44. Sarma, R. H., Dannies, P. \& Kaplan, N. O. Investigations of inter- and intramolecular interactions in flavin-adenine dinucleotide by proton magnetic resonance. Biochemistry 7, 4359-4367 (1968).

45. Moonen, C. T. W., Vervoort, J. \& Muller, F. Reinvestigation of the structure of oxidized and reduced flavin - C-13 and N-15 nuclear magnetic-resonance study. Biochemistry 23, 4859-4867 (1984).

46. Guttman, D. E. Complex formation influence on reaction rate 1. Effect of caffeine on riboflavin base-catalyzed degradation rate. J. Pharm. Sci. 51, 1162-1166 (1962)

47. Esswein, A. J. et al. Aqueous redox flow batteries featuring improved cell design characteristics. US patent 8691413 (2014).
48. Esswein, A. J., Goeltz, J., King, E. R., Reece, S. Y. \& Amadeo, D. Aqueous redox flow batteries comprising metal ligand coordination compounds. US patent 8753761 (2014).

49. Cao, C. Y., Wang, H. B., Liu, W. W., Liao, X. Z. \& Li, L. Nafion membranes as electrolyte and separator for sodium-ion battery. Int. J. Hydrogen Energy 39, 16110-16115 (2014).

50. Sakai, M. \& Ohnaka, N. Kinetics of the second charge transfer step in an EE mechanism by rotating ring-disk electrode voltammetry. J. Electrochem. Soc. 137, 576-579 (1990).

\section{Acknowledgements}

UCSD team gratefully acknowledges the funding from Advanced Research Projects Agency-Energy (ARPA-E) under Grant No. DE-AR0000520. A.O. and Y.S.M. acknowledge the partial funding from Hitachi Chemical.

\section{Author contributions}

A.O. conceived and conducted the research, and A.O. and M.G.V. designed the experiments. All authors discussed and analysed the results. A.O., M.G.V. and Y.S.M. wrote the manuscript.

\section{Additional information}

Supplementary Information accompanies this paper at http://www.nature.com/ naturecommunications

Competing financial interests: The authors declare no competing financial interests.

Reprints and permission information is available online at http://npg.nature.com/ reprintsandpermissions/

How to cite this article: Orita, A. et al. A biomimetic redox flow battery based on flavin mononucleotide. Nat. Commun. 7, 13230 doi: 10.1038/ncomms13230 (2016).

(c) (i) This work is licensed under a Creative Commons Attribution 4.0 International License. The images or other third party material in this article are included in the article's Creative Commons license, unless indicated otherwise in the credit line; if the material is not included under the Creative Commons license, users will need to obtain permission from the license holder to reproduce the material. To view a copy of this license, visit http://creativecommons.org/licenses/by/4.0/

(C) The Author(s) 2016 